\title{
Using CCTV to study visitors in The New Art Gallery, Walsall, UK.
}

\author{
Ela Beaumont1
}

\begin{abstract}
The routine use of CCTV surveillance in new art galleries in the UK presents an opportunity for researchers to harness its potential as a powerful observational tool in visitor studies, and recent developments in video technology have created new possibilities for observational research. Recent studies using video observation methods in the UK, France and the US have demonstrated how powerful film data can be, but have also shown the difficulties in operationalising studies that use these techniques. The analysis of video data is in its infancy in the field of art gallery visitor studies, and this paper contributes to the theoretical, ethical and practical debate by discussing a recent observational visitor study using in-house CCTV cameras in the New Art Gallery, Walsall. The study demonstrates significant advances on previous observational visitor studies that have gathered 'covert observational data'. It show how CCTV footage can be used to gather naturally occurring visitor activities in a highly structured way, without disrupting the gallery with extra cameras or microphones and yielding increasingly detailed, useful information. It opens up the prospect of a wider ideological debate about the use of CCTV in art galleries, and contributes to work in progress on a code of ethics for video observation in visitor studies.
\end{abstract}

\section{Introduction}

Observation is a fundamental tool in visitor studies for researching both human activities and the physical setting in which such activities take place (Angrosino and de Perez, 1997). The use of ethnographic observational techniques represents one of the longest established traditions in social science research, and whilst early observational field work relied on notebook and pencil, more recently, cameras (still and movie) have augmented the ethnographer's tool box. I will argue that the routine use of CCTV surveillance in art galleries in the UK presents an opportunity for researchers to harness its potential as a powerful observational tool in visitor studies, and that recent developments in video technology have created new opportunities for observational research. The analysis of video data is in its infancy in the field of art gallery visitor studies, and this paper aims to contribute to the theoretical, ethical and practical debate by discussing a recent observational visitor study using in-house CCTV cameras in the New Art Gallery, Walsall.

\footnotetext{
${ }^{1}$ Adelphi Research Institute, School of Art and Design, University of Salford, UK. mailto:e.beaumont@salford.ac.uk
} 
There are differences between using CCTV filming as an observational method in visitor studies and the wider use of CCTV for the maintenance of public order. All surveillance tries to make visible the behaviours of people of interest to the agency in question (Lyon 2002). This study was interested in family group visitors, and CCTV was used within the strict boundaries of the terms of reference of the research, only coding specific information on the behaviours of the sample, ie. family group visitors to the New Art Gallery, Walsall. Other behaviours by other groups in the gallery, which were captured on CCTV during the research filming, for example groups of young people playing in the lifts or moving exhibits were not coded because they fell outside the scope of the investigation. The gallery is governed by Walsall Metropolitan Borough Council and formal permission was granted by Walsall MBC for CCTV footage to be used for research purposes, on the understanding that using the CCTV as an investigative tool for research was secondary to surveillance, which would take priority if necessary. Security staff monitored the CCTV concurrent with the research study, and there are occasional gaps in the video footage where the cameras swung round to focus on behaviour outside of the research study, that security staff considered inappropriate.

\section{Background}

Britain is one of the most watched nations in the world, with over 4 million surveillance cameras in use (Norris et al., 2004). In 2004, The Council for Museums, Archives and Libraries in the UK, published guidelines for the use of CCTV in museums, suggesting that the main advantages that accrue from CCTV are: deterrence, an aid to invigilation, recording for post-incident investigation, entry control and site management out of hours (Resource, 2004). In this context, surveillance is understood as 'the purposeful watching of specific individuals who have aroused suspicion' (Lyon, 2001). New Art Gallery, Walsall, used CCTV as a security measure in the way described above, and we proposed to carry out a visitor study using the existing CCTV surveillance system within the New Art Gallery as an observational research tool. Utilising the New Art Gallery in-house CCTV system, this research made significant advances on previous observational visitor studies that have gathered 'covert observational data' (Office of Information Commissioners, 2002).

Definitions of surveillance include the 'close observation, especially of a suspected person' (Concise Oxford Dictionary), yet much contemporary surveillance is 'not applied especially to a suspected person' (Marx, 2002). This visitor study embraced existing surveillance technology rather than setting up additional systems with extra cameras. Earlier video observational research has attempted to reduce the effect of video cameras on visitor's conduct by hiding them (Vom Lehn et al., 2002), and in attempting to gather audio tapes of natural speech, previous studies have had problems obtaining good quality acoustic data (Allen, 2002). Solutions such as getting visitors to wear microphones and carry tape recorders bring their own difficulties in ensuring naturalistic responses. This study of visitors to the New Art Gallery, Walsall, obtained good quality visual data from CCTV and used face-to-face interviews for verbal information. 
There are a number of constraints upon using CCTV for research purposes, primarily relating to how data are collected and handled, including the legal requirements of 'informed consent'. However, we took the view that as the surveillance equipment was already constantly monitoring visitors to New Art Gallery, Walsall, whilst they were in the art gallery, this additional interrogation of their images for research purposes was a legitimate use of the CCTV footage. We modified the definition of surveillance offered above, to 'the purposeful watching of specific individuals' For this study, the specific individuals were visitors coming to the New Art Gallery, Walsall.

\section{Antecedents}

A pioneering study of observational methods in the early days of visitor studies research highlighted the advantages of filming visitors. In 1942 at the University of Chicago, Neilson, an education research associate in the Museum of Science and Industry, identified the need for comprehensive visitor studies, suggesting that visitors themselves remain the least known, most unpredictable and most difficult aspect of museum work to study. He suggested that the method of determining how museum visitors react should be observation in the context of specific museum situations. However, he found there were four main limitations to traditional observation and tracking studies involving following visitors with notebook and stopwatch:

- High financial implications of training and maintaining staff

- Large number of hours necessary and the difficulty of the work

- Variable or unreliable data

- Inefficient yield of data related to hours of work

(Neilson, 1942)

Neilson proposed an alternative technique for observing visitors; that of time lapse photography. He mounted a movie camera equipped with single-exposure release high in one corner of the gallery, concealed as much as possible from visitor's view. The resulting film, a series of snapshots of the entire room, provided a record of all activities in the gallery, showing exactly:

- How many visitors entered the gallery

- How many there were at any given moment

- Where visitors went and in what sequence

- How they looked at the exhibits

- How long they stayed at each exhibit

- How long they stayed in the gallery as a whole

Neilson found that this data on film could be analysed and transcribed a number of times whilst looking for different aspects of visitor behaviour. 


\section{Current video observational research}

Observing visitors as a method in visitor studies research has its origins in anthropological and ethnographic investigations and observational and tracking studies have the great advantage that they can be administered unobtrusively. Visitors may be entirely unaware that they are being observed, though ethics demand that there be a sign somewhere prominent drawing visitors' attention to the fact that there is a study taking place.

There is a long-standing interest in using video recording for the observational study of visitor behaviour (Vom Lehn et al., 2002). Neilson's early work in the 1940's has already been mentioned. Following Shettel's work in the 1960's and Hensel (1987) and Leichter et al. (1989) in the 1980's, researchers have used video to record visitors' navigation paths, how they look at exhibits and their patterns of behaviour (Falk, 1991; McManus, 1994; Phillips, 1995). The use of video technology principally replaces an in-situ observer with a camera and the great advantage of this method is the facility for the researcher to repeatedly view events away from the research site. As Vom Lehn (2002) has pointed out, the video camera augments the work of the observer, and, by recording at different times on different days, a substantial amount of data can be gathered and subsequently analysed. The technology makes it possible to record and analyse with a degree of particularity not available to the field researcher. In research of this type, the video camera does not supplant the observer, rather, the field observation is enhanced by the video data.

Recently video observation methods have been used by Heath (2002) in the Victoria and Albert Museum and the Science Museum in London, Gutwill-Wise (2002) at the Exploratorium in San Francisco, and Vom Lehn et al. (2002) at @Bristol in the UK and the Musee des Beaux Arts in Rouen, France. These studies have demonstrated how powerful film data can be, but have also shown the difficulties in operationalising studies that use these techniques. However, for some types of study, the benefits outweigh the difficulties $^{2}$ and the value of using video footage to investigate visitors is that it provides:

- a non-intrusive method of studying visitor behaviour

- an opportunity to examine visitor behaviour in different exhibitions in the same gallery

- stable evidence that can be viewed repeatedly

- data that can be replicated and re-examined

Video recording also captures, in real-time, visitor behaviour as it arises in a naturalistic setting. Details and patterns appear through intense and repeated scrutiny of the tapes which, as raw material, can be analysed by the research community in order to judge the reliability of findings based on the video data. But despite its potential as a research tool, collecting video data remains relatively unexplored within visitor studies for three reasons:

2 Difficulties include; gaining approval, ethical issues, minimising disruption to normal surveillance activities, briefing and training operators, retrieving and storing data, and data analysis. 
- The technical problems associated with obtaining good quality recordings in art gallery and museum settings (Phillips, 1995; Vom Lehn et al., 2001)

- The analysis of video data is extremely time consuming (McManus, 2001; Allen, 2002)

- Visitors react to the camera and their behaviour becomes unnatural (Smith and Wolf, 1996)

In relation to the latter point, Borun and her colleagues (1997) audio and videotaped parents and children at the Franklin Institute in the United States as part of a family learning project, but if people realized they were being observed the observation was ended by the researcher and deleted from the sample because the observation was considered to be corrupted (Borun et al., 1997). There are also potential analytical weaknesses associated with observational method, which are:

- Lack of rigorous design

- Large amounts of poorly collected and unanalysed data

- Superficial and hasty conclusions (Miles and Huberman, 1994)

\section{Using CCTV for research at the New Art Gallery, Walsall}

All the studies referred to above involved setting up camera equipment specifically for the research project. This study in New Art Gallery, Walsall engaged with CCTV creatively as an observational tool to study visitors within art galleries by utilising the existing surveillance cameras. It opens up the prospect of a wider ideological debate about the use of CCTV in art galleries, and contributes to work in progress on a code of ethics for video observation in visitor studies (Gutwill-Wise, 2002).

The 'real time availability' of the observational data, which Marx (2002) suggests is a feature of the 'New Surveillance', was an advantage in this visitor study, and offered the opportunity to integrate data collection for research into the routine surveillance activity of the gallery (within the Office of the Information Commissioners CCTV Code of Practice guidelines). The pre-existing presence of cameras at the research site meant that gathering observational data through New Art Gallery, Walsall's internal CCTV security system was a distinct possibility. In consultation with the curatorial staff, front of house staff and security staff it was agreed that a CCTV camera in a gallery on the third floor would provide the most comprehensive data with least disturbance to the normal functioning of the CCTV cameras as front line security. There were 2 major advantages to using in-house CCTV in this visitor study:

- technical problems associated with obtaining good quality recordings had already been addressed and solved by the technical staff at the New Art Gallery

- CCTV cameras are discreet compared to bulky and often obtrusive video equipment

The case study at New Art Gallery, Walsall was tightly focused with the intention of gathering information about a particular group in a particular context within a particular time frame and analysis of the video observations used methods that provide an 
alternative to the extensive written notes that are the hallmark of traditional ethnographic inquiry (Nastasi, in Schensul et al., 1999).

\section{Ethical Considerations}

The decision to use CCTV for the current research project was taken with the intention of minimising the intrusiveness of the filming without, however, compromising visitor's right to give their informed consent. The study took place in the 'real world of ethical tensions' (Lyon, 2002), where, for example, the disclosure of images recorded by CCTV is restricted to uses compatible with the original reason for obtaining the images (France, 2000). In relation to videotaping visitors during observational and tracking studies, recent guidelines suggest that informed consent explaining the nature of the study is required. However, research studies have shown that informed consent can be undocumented or implied as long as signs are posted in the recorded areas (Heath, 2002; Gutwill-Wise, 2002).

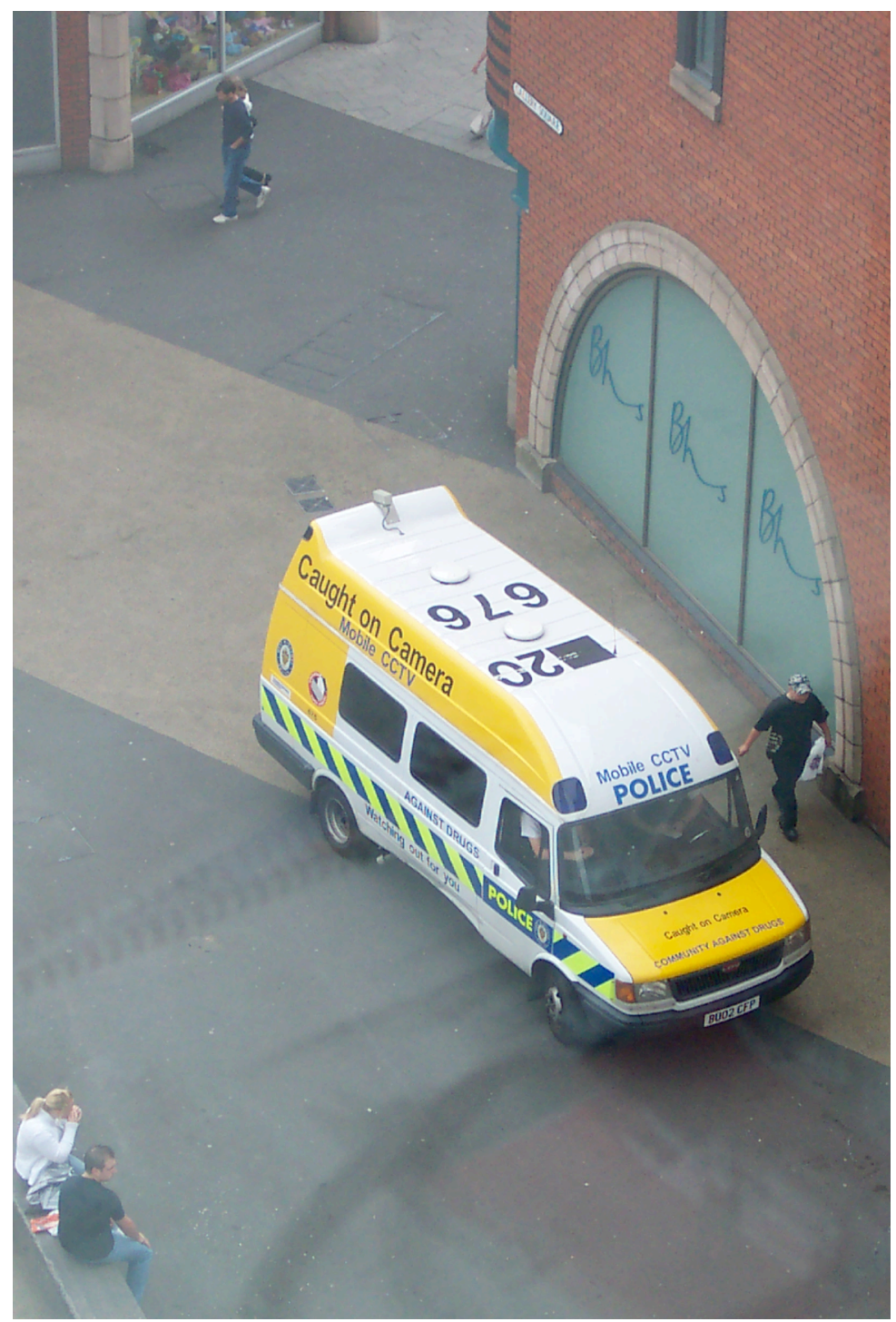

\section{Figure 1:}

The view from the third floor of the New Art Gallery, Walsall. The police surveillance van was regularly parked directly outside the gallery entrance. 
The advantage for the current study in using CCTV film was, as suggested above, the prevalence of surveillance in public spaces in the UK (Figure 1). CCTV surveillance is generally perceived as a benign activity in the UK (Norris, 2004), and we took the view that by posting signs telling of the research, and in not disrupting the gallery with extra cameras or microphones, the CCTV footage would gather naturally occurring visitor activities in a highly structured way, yielding increasingly detailed, useful information.

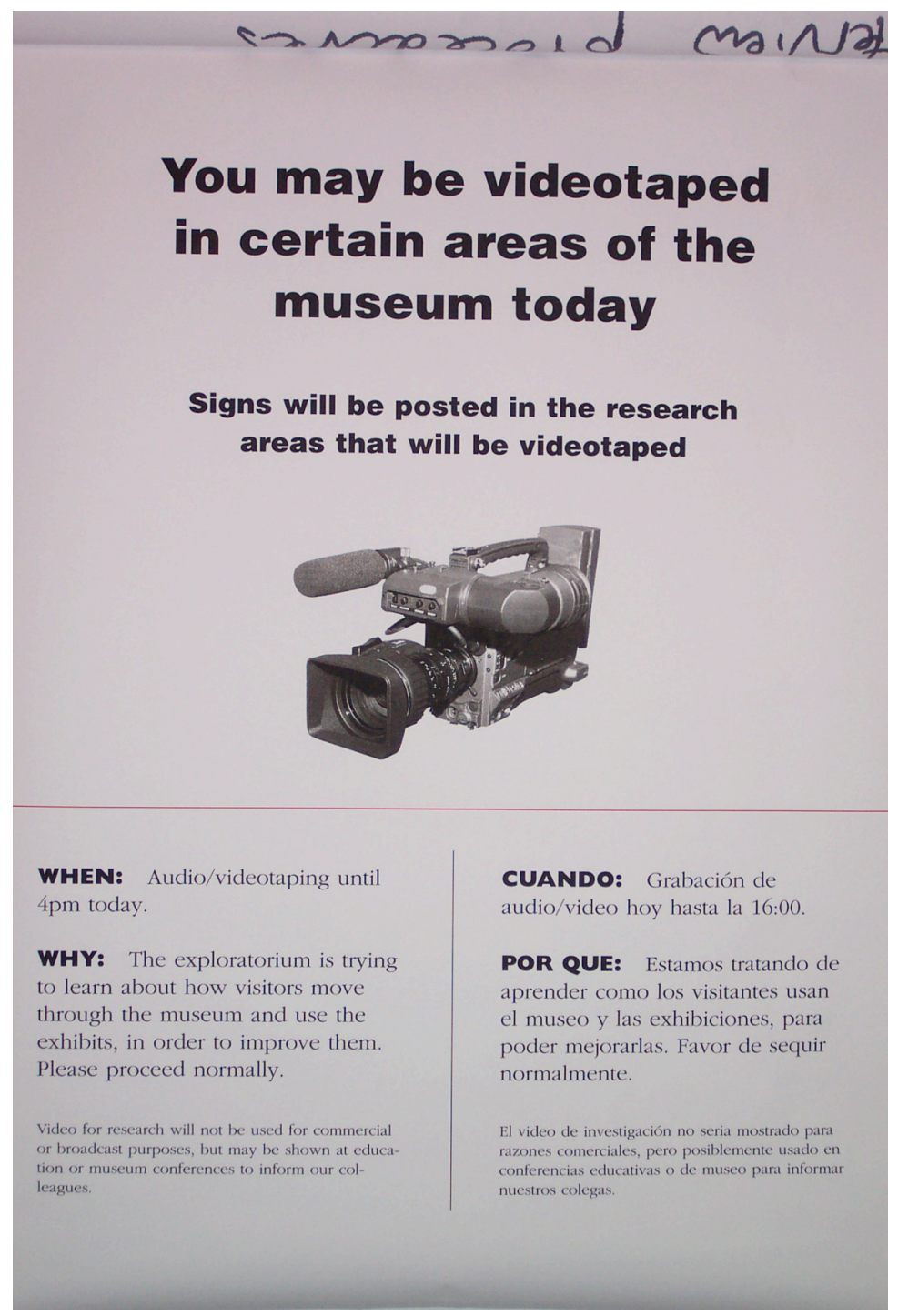

Figure 2:

First poster at the Exploratorium in San Francisco alerting visitors to the study. The posters are in Spanish as well as English because a large number of visitors have Spanish as their first language.

Usually video observation relies on equipment that is very visible and therefore intrusive. Visitors are aware of being filmed when video equipment is set up at the research site, and the protocols for filmed observation are constantly evolving and being refined through action research in light of emerging ethical considerations (Gutwill, 2002). The figures below show the posters devised for research into visitors at the Exploratorium in San Francisco. Figure 2 shows the original poster, figure 3 shows the poster modified because researchers found visitors had not noticed the first one. 


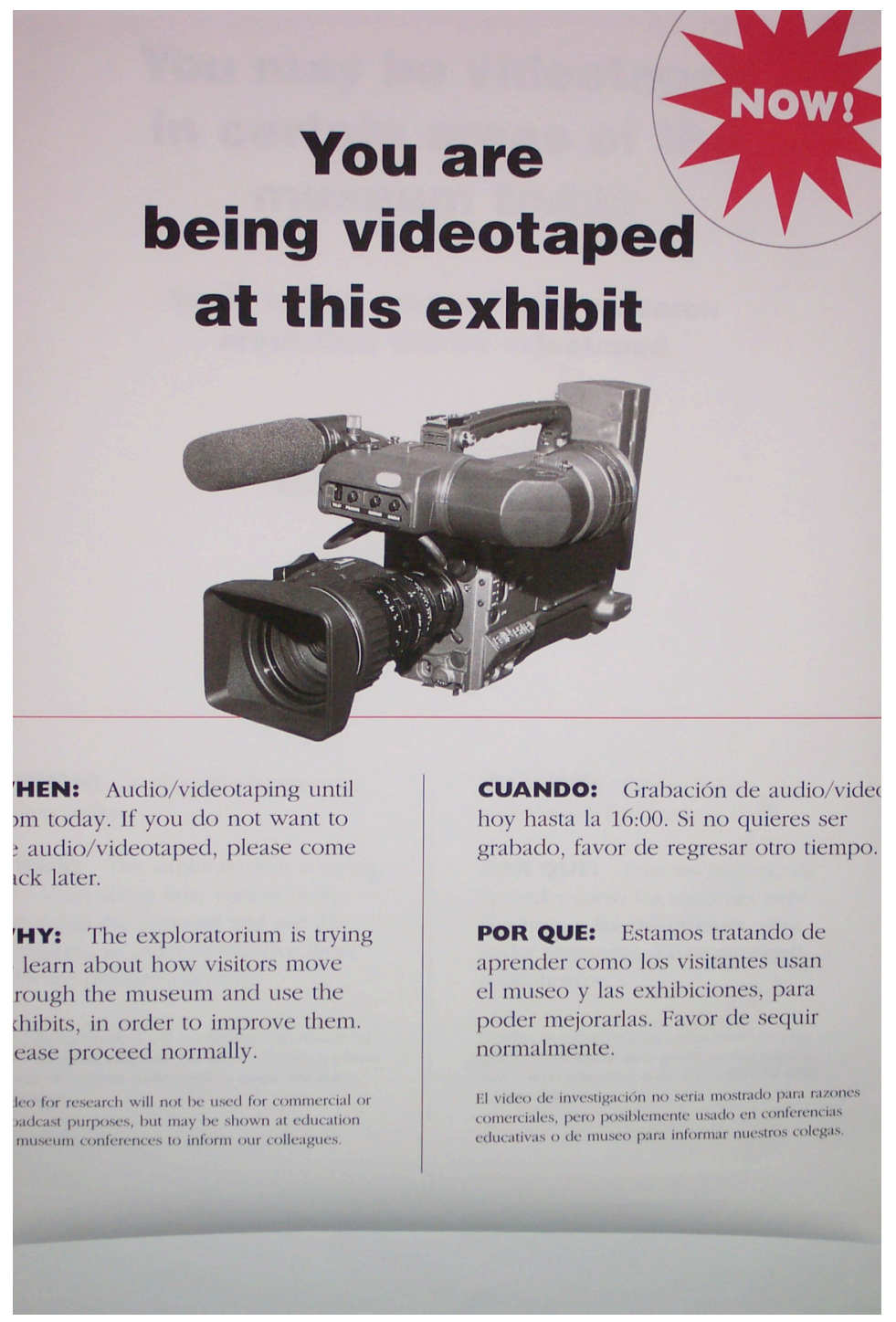

Figure 3: Second poster devised after it was discovered the first poster was not noticed by visitors

Both in the United States and the UK, researchers need to consider the size and placing of signs which alert the public that they are entering a zone covered by surveillance equipment. Even large signs, with images of cameras, as shown above, are not always noticed by the public, and in any case, the First Data Protection Principle (UK) suggests that in certain circumstances, a written A4 sign at eye level may be enough (France 2000).

Ethical principles in 'action research' have been summarised in the context of visitors and visitor studies by Bicknell and Gammon (1995) through their research in the Science Museum in London. This study in the New Art Gallery, Walsall, took account of the following principles:

- Observing protocol

- Including participants

- Negotiating with those affected

- Reporting progress 
- Obtaining explicit authorisation before observing

- Obtaining explicit authorisation before examining files, correspondence or other documentation

- Negotiating descriptions of people's work

- Negotiating accounts from other points of view

- Obtaining explicit authorisation before using quotations

- Negotiating reports for various levels of release

- Accepting responsibility for maintaining confidentiality

- Retaining the right to report work

- Making principle and procedures known and binding

Extensive discussions with key personnel concerning exactly how visitors are informed and how to gain their cooperation will always be needed when filming is part of a research strategy. Particular protocols need to be developed in relation to the use of CCTV footage as the film is being used for a purpose other than that for which it was originally intended (France, 2000). The use of images derived from surveillance technology, albeit not applied to 'close observation of a suspected person' (Concise Oxford Dictionary, 1998) needs careful treatment. The Data Protection Act of 1998, and subsequent interpretations of it, requires those who operate CCTV systems and who record images from which individuals can be identified through 'personal data' to register with the Information Commissioner (Taylor, 2002). 'Personal data' means:

Any information relating to an identified or identifiable natural person; an identifiable person is one who can be identified, directly or indirectly, in particular by reference to an identification number or to one or more factors specific to his physical, physiological, mental, economic, cultural or social identity (European Directive 95/46/EC).

Evidence from other recent visitor studies suggests that researchers regard videotaping and the use of CCTV images for ethnographic methods for research purposes as ethically neutral (Angrosino and Perez, 1997). But three criteria should be applied to test for the probity of research which uses such methods:

- The means will not cause more harm than necessary to achieve the value

- No less harmful way exists at present to protect the value

- The means used to achieve the value (result) will not undermine it (Herrera, 1999)

In the context of studying human actions, the above criteria gives such research its moral meaning, 'in that sense proportionate refers to the specific value at stake and the limitations, the harm, or the inconvenience which will inevitably come about in trying to achieve that value' (Craig et al., 2000).

\section{Practical considerations}

In consultation with security staff at the New Art Gallery, Walsall, we felt that the notice at the front of the gallery, informing visitors that CCTV cameras were in 
operation was not sufficient to gain implied consent (Figure 4), particularly as the notice was almost completely obscured by the front door as it opened to admit visitors (Figure 5, overleaf).

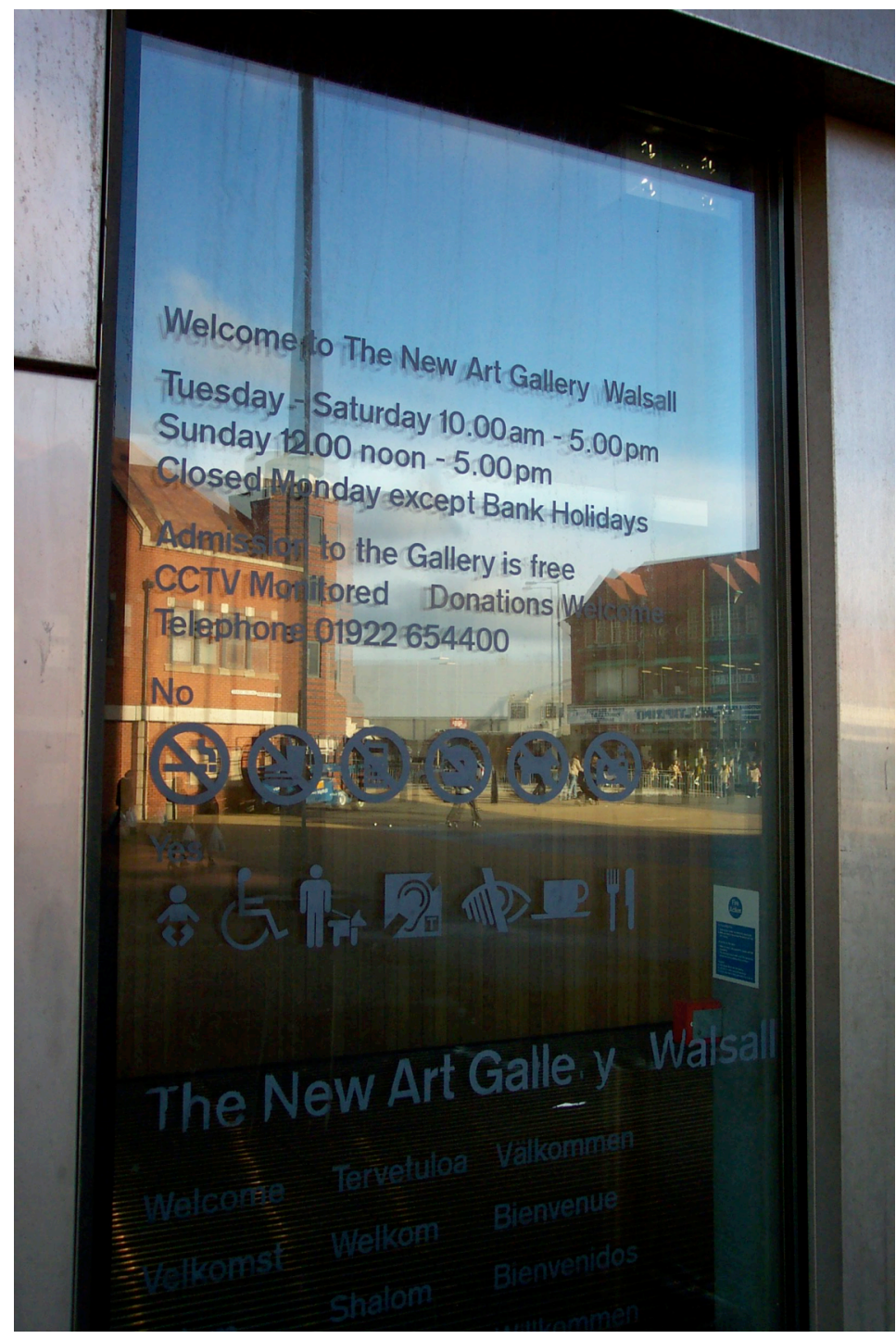

Figure 4: Notice outside the gallery showing that CCTV cameras are in use

In discussion with senior gallery staff, the agreed procedure was to place a notice at the entrance to the gallery under investigation. The notice informed visitors about the research and invited those with reservations about the research to speak to an attendant. In practice, researchers have found that visitors do not object to the use of video in the conduct of research (Gutwill, 2002; Allen, 2002; Vom Lehn, 2002; Beaumont, 2004). 


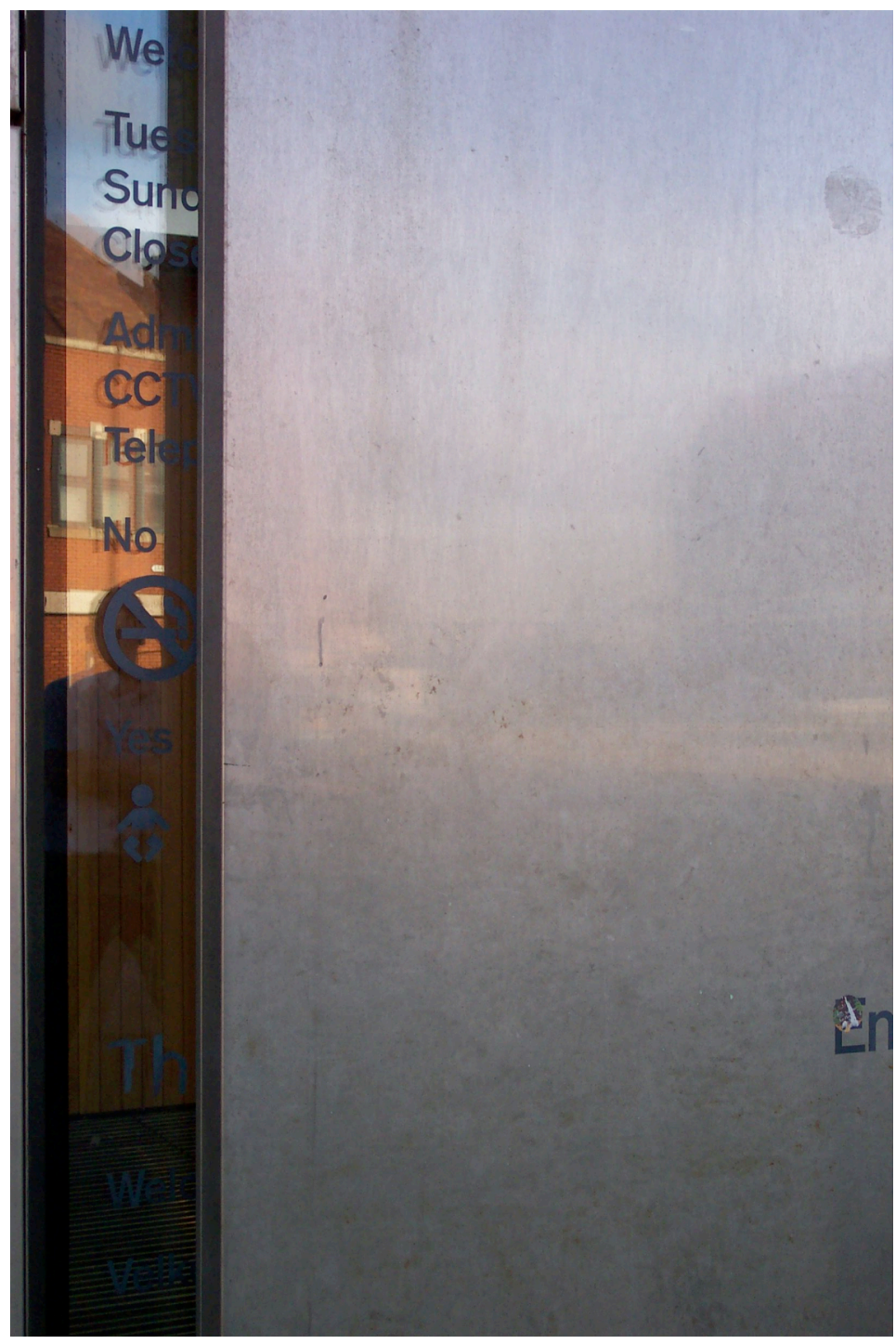

Figure 5: Door obscuring the CCTV camera notice

CCTV filming has not been used extensively as an observational method in visitor studies to date and had not been used before in the New Art Gallery, Walsall. The gallery is governed by Walsall Metropolitan Borough Council and a risk assessment was carried out with the Risk and Insurance Officer at Walsall MBC. Formal permission was granted by him on behalf of Walsall MBC for CCTV footage to be used in this way. Ironically perhaps, whilst granting permission for video research to take place in the gallery, Walsall MBC was also making the decision to withdraw photographs by the Moscow-based EAS group from the 'Veil' exhibition, fearing they were too controversial in the current climate, post September $11^{\text {th }}$ (fig 6). 


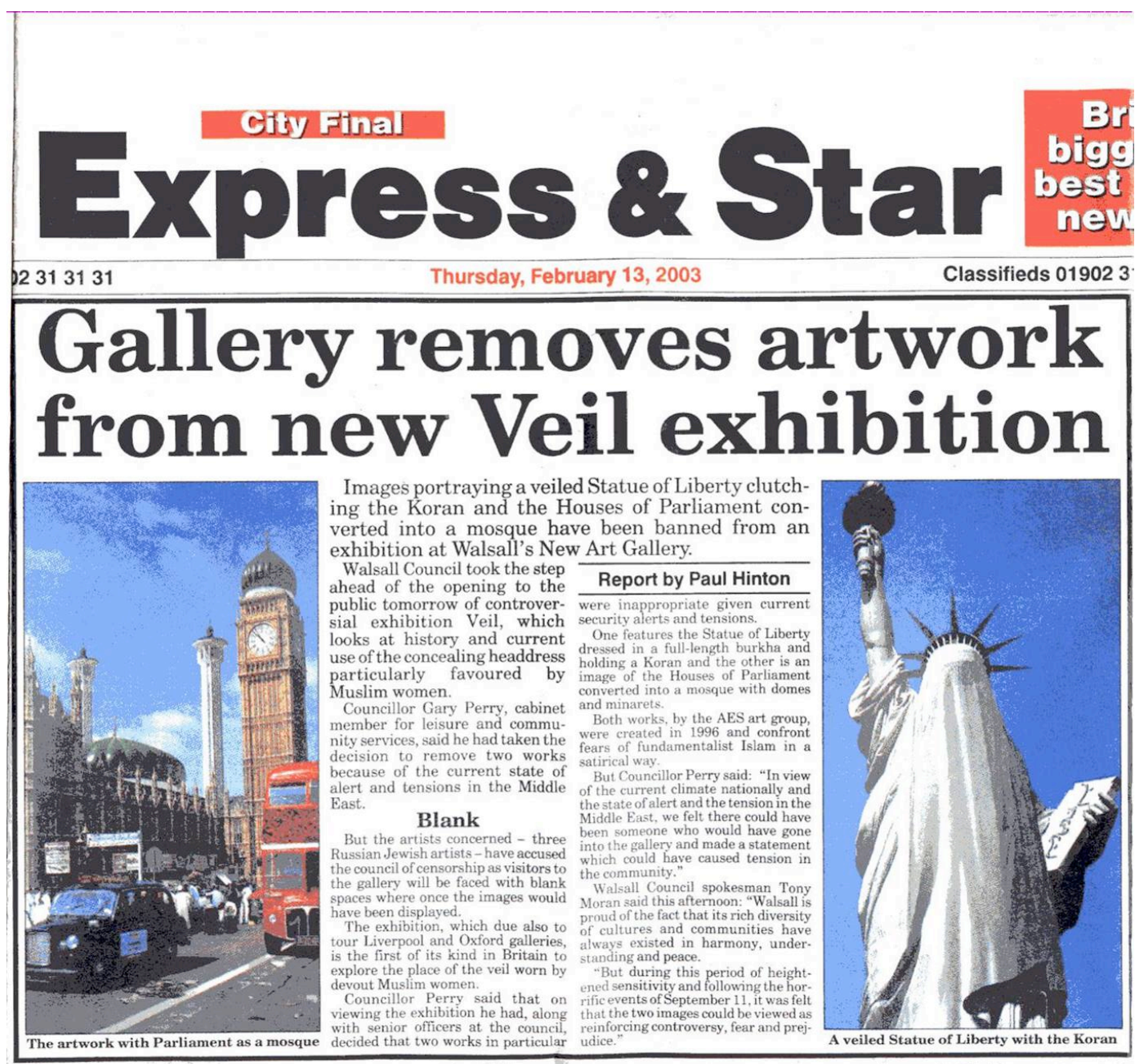

Figure 6: Two photographs were removed from the Veil show by Walsall MBC

Significantly, some contemporary artists have responded to the implications of widespread CCTV surveillance, and their work shown in art galleries in the form of photographs, video and multimedia (Naldi and Kirkup, 1993; Stidworthy, 2004). Art galleries are 'laboratories for the study of value in art' (Ueki, 1998) and this study of the New Art Gallery, Walsall, contributes to the ongoing debate about the purpose of art galleries and the role of the art gallery in contemporary society, in particular the context in which contemporary art is viewed.

\section{Camera position}

Neilson, in his early study, was not able to obtain a wide angle camera, so he mounted the camera backwards, pointing towards a large convex mirror that reflected the image of the gallery (Figure 7). For the present study the CCTV camera coverage poses no such problem. The wide angle of the camera shows the whole gallery with the exception of a small area directly under the camera (Figure 8). Three hour VHS videotapes provide data that can be analysed time and again without being transcribed into tabular form. 


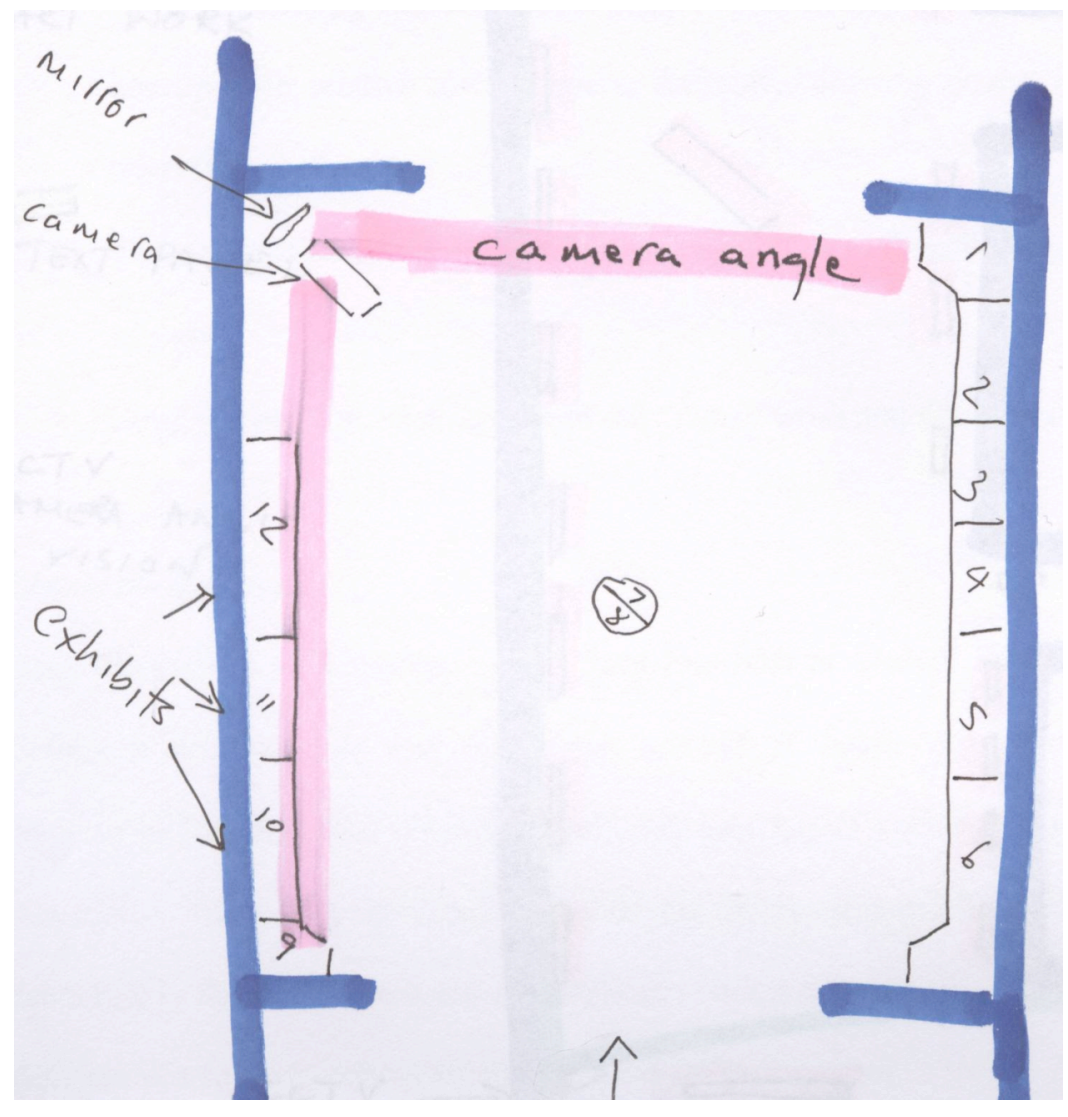

Figure 7: Diagram showing the camera angle in Neilson's study

Figure 8: Diagram

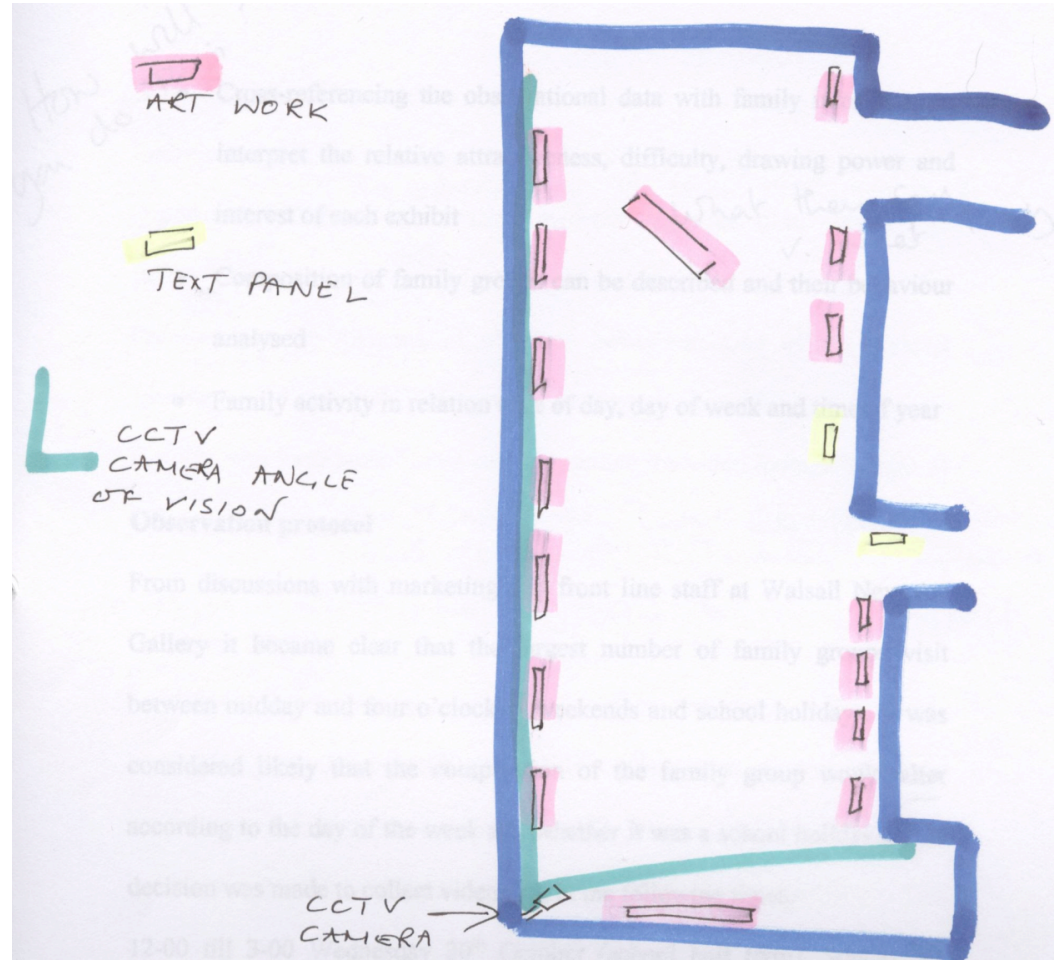
showing the CCTV camera angle at the cases study site, New Art Gallery, Walsall 
Sample size

Another potential problem with observational methods relates to stability and instability of observed behaviour. It is commonly assumed that behavioural observation provides a typical sample of behaviour, but the sample of behaviour may not be representative. In general, the larger the sample of behaviour, the more representative and accurate the sample of behaviour becomes (Holden and Edwards, 1989). Systematic studies of observational data on parent-child interactions, for example, have found that the more observations are combined, the more stability of behaviour increased (Touliatos et al., 1990). In this study, a sample number was selected that would be sufficient to gather information about general trends, but small enough to analyse in great detail.

\section{Coding observational data}

In the New Art Gallery, Walsall study, observational video data used in conjunction with questionnaire surveys and in-depth interviews increased both reliability and validity. The overall methodological approach used in this study provided rich material, generating both quantitative and qualitative data. In applied fields such as visitor studies, there is often compatibility between qualitative and quantitative research in practice (Robson, 2002), and advantages to mixed method research design. There are many questions related to visitor behaviour and interaction where observation would be the preferred method (Lytton, 1971), but observational methods continue to be rare for two reasons:

- The approach requires more knowledge than other methods

- A considerable investment in time and training is needed in observation and coding data

Observing visitors usually involves an initial study to establish visitor behaviours that relate to the area of investigation, and the list of interesting visitor behaviours refined and often coded. Direct observation also includes the need to develop a set of observation methods that can accurately record the behaviours under investigation. Behavioural categories need to be defined carefully so that the method is reliable

Investigators usually conduct a series of preliminary observations during which all behaviours are recorded. These can be compared to lists of behaviours published in previous studies and a protocol and observation schedule developed accordingly.

The observation schedule consists of data sheets based on the floor plan of the study site. The purpose of this is to collect information in a systematic manner (Serrell. 1998). Observational data sheets are typically hand drawn and not to scale, but contain information relevant to the study. At New Art Gallery, Walsall, each observed visitor was allocated a unique number based on the video time code in the top left hand corner of the video image. For example, Figure 9 (overleaf) shows the observational data sheet relating to a grandmother and granddaughter visitor group; their unique number is $30.5 .03,13.00 .51$ which indicates the exact date and time they entered the gallery. Figure 10 (p.266) shows how the observations of the same group are recorded on video: further reviewing of the data involves simply locating the number on the videotape. This system prevents accidental transposing of information 
about visitors and allows for quality checks to be made, but crucially means that demographic and attitudinal data collected elsewhere can be correlated to the video data on visitor behaviour.

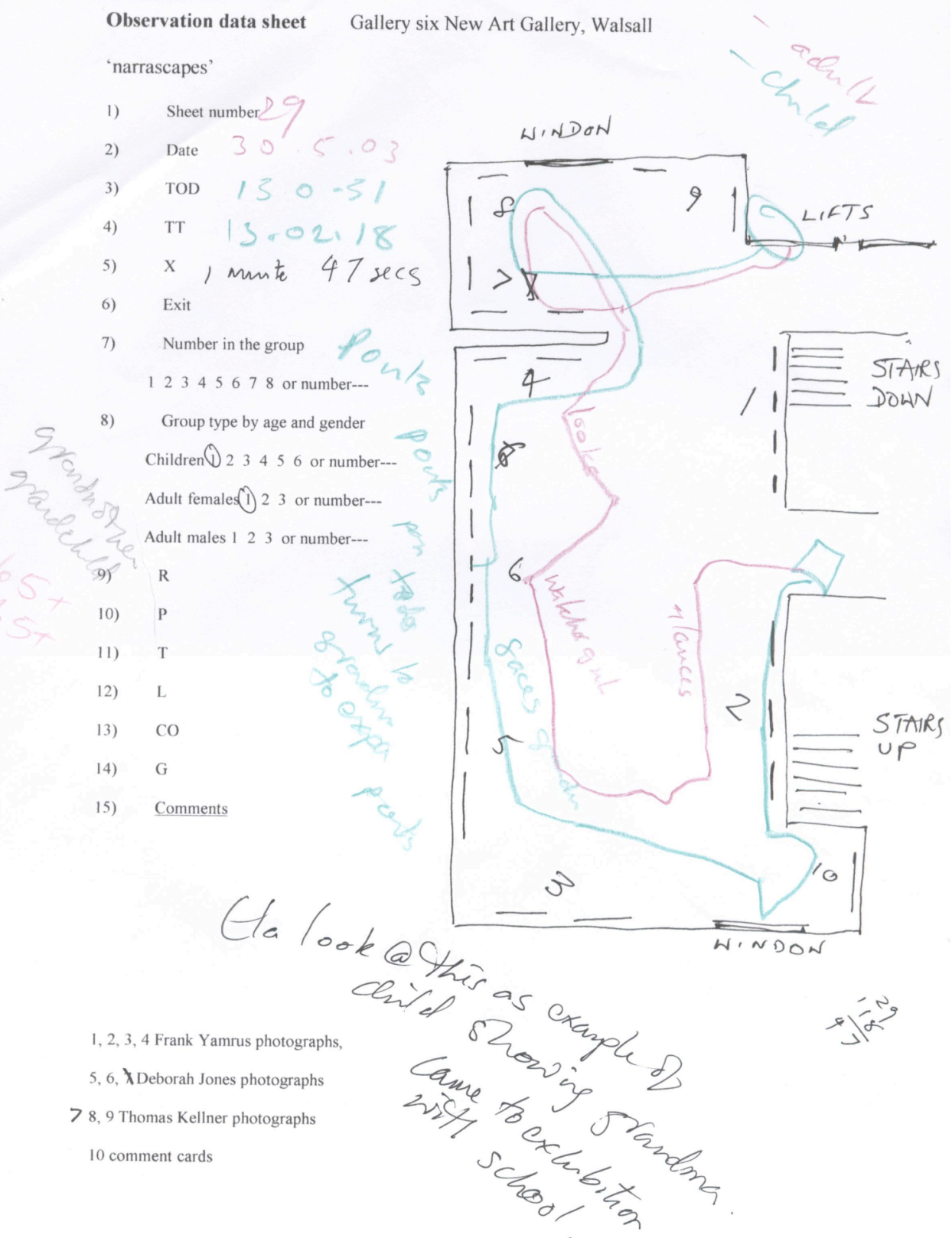

Figure 10: Observation sheet No. 29 from the 'narrascape' show 


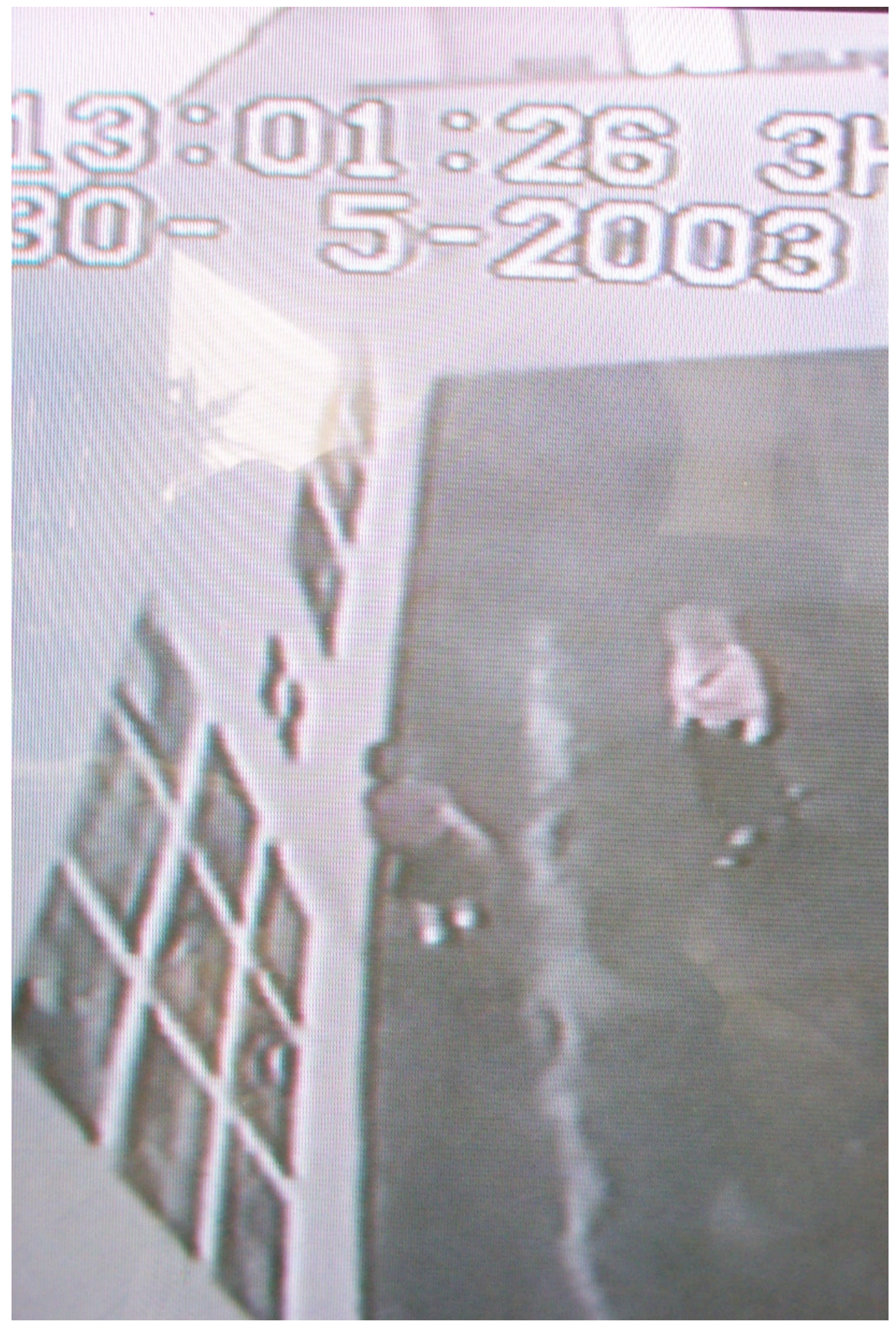

Figure 10: CCTV video image of visitors, showing their unique reference number (which relates to the observation sheet)

This method of coding data was particularly important because interviews took place concurrently with video observation. The time code enabled video observation to be 
matched with interview data on individual visitors without compromising their anonymity.

\section{Conclusion}

The contribution of this study of visitors to the New Art Gallery, Walsall, has been to focus on the behaviour of visitors to a newly built regional art gallery using CCTV video observation. Despite the growing body of research into visitors, we still know relatively little about the action and interaction arising between visitors as they encounter exhibits (Vom Lehn, 2002), At the New Art Gallery, Walsall, the technological sophistication of pre-exisiting CCTV coverage was identified as having great potential as an observational tool for visitor research. Combined with other methods within a case study strategy, the observational CCTV information yielded valuable data about visitors to a significant new regional gallery. New galleries devoted to modern and contemporary art have been established relatively easily, they are glamorous, they reflect a general shift of interest towards modern and contemporary art (Shubert, 2000) and they manifestly produce results by attracting large audiences in the short term. The period between 1994 and 2004 represents a remarkable cultural moment in the UK, and this detailed observational case study of visitors to the New Art Gallery, Walsall provides insights into visitor behaviour at an important regional millennium project.

Reeves (2002) recently suggested, in her wide-ranging review of current research initiatives for the Art Council in England, that there is scope for developing a national framework for visitor research which builds on the methodological strengths and practical experience of the best UK studies. Her report concluded that there is a need for more research that utilises both quantitative data and qualitative description, and a need for more in-depth case study research. This study contributes to the developing field of visitor studies in the UK and internationally by offering an original but replicable observational method using in-house CCTV.

\section{References}

Allen, S. (2002) Looking for Learning in Visitor Talk: A Methodological Exploration In Leinhardt, Crowley and Knutson (eds.) (2002) Learning Conversations in Museums. New Jersey: Lawrence Erlbaum.

Angrosino, M.V. and de Perez, K.A. (1997) Rethinking Observation: From Method to Content In Denzin and Lincoln (eds.) Handbook of Qualitative Research London: Sage.

Beaumont. E.T. (2004) An Empirical Study of Family Group Visitors to a Millennium Art Gallery. Unpublished PhD Thesis, University of Salford, UK.

Bicknell, S., and Gammon, B. (1995) Ethics and Visitor Studies- Or Not? Visitor Studies: Theory, Research, and Practice, $8(1)$ :

Borun, M., M. Chambers et al. (1997) Enhancing family Learning through Exhibits. Curator 40(4): 279295. 
Craig, G., A. Corden and P. Thornton (2000) Safety in Social Research. Social Research Update 29.

Falk, J. (1991) Analysis of the Behaviour of Family Visitors in Natural History Museums. Curator 34(1): 44-50.

France, E. (2000) Office of the Information Commissioners CCTV Code of Practice Guidelines. London: OIC.

Gutwill-Wise. J. (2002) Audio/videotaping Museum Visitors: Methods for Obtaining Informed Consent. Presentation at the Visitor Studies Conference 2002, Cody, Wyoming.

Heath, C., P. Luff, et al. (2002) Crafting Participation: designing ecologies, configuring experience." Visual Communication 1(1): 9-34.

Hensel, K.A. (1987) Families in a museum: Interactions and conversations at displays. Unpublished PhD Thesis, Columbia University Teachers College, New York.

Herrera, C.D. (1999) Two Arguments for 'covert methods' in social research. British Journal of Sociology 50 :

Holden, G.W. and Edwards, L. (1989) Parental attitudes towards childrearing: Instruments, issues and implications Psychological Bulletin 106: 29-58.

Leichter, H. J., Hensel, K. And Larsen, E. (1989) Families and Museums: Issues and Perspectives. In Marriage and Family Review-Museum Visits and Activities for Family Life Enrichment 1989, Hawarth Press, New York

Lyon, D. (2001) Surveillance Society: Monitoring Everyday Life. Buckingham: Open University Press.

Lytton, H. (1971) Observational Studies of Parent-Child Interaction: A Methodological Review Child Development 42(3): 651-684

Marx, G.T. (2002) What's New About the 'New Surveillance'? Classifying for Change and Continuity Surveillance and Society 1(1): 9-29. http://www.surveillance-andsociety.org/articles $1 /$ whatsnew.pdf

McManus, P. (1994) Families in museums. In R. Miles and L. Zavala (eds.) (1994) Towards The Museum of the Future London: Routledge.

McManus, P. (2001) Getting to Know Your Visitors. Association for Heritage Interpretation. www.heritage-interpretation.org.uk

Miles, M.B. and A.M. Huberman (1994) Qualitative Data Analysis. Thousand Oaks, CA: Sage.

Naldi, P. and W. Kirkup (1993) Search Surveillance Still. Installation in the Second Tyne International, Newcastle.

Neilson, L.C. (1942) A Technique for Studying the Behaviour of Museum Visitors Journal of Educational Psychology 37: 103-110.

Norris, C., M. McCahill and D. Wood (2004) 'Editorial. The Growth of CCTV: a global perspective on the international diffusion of video surveillance in publicly accessible space,' Surveillance \& Society 2(2/3): 110-135. http://www.surveillance-and-society.org/articles2(2)/editorial.pdf

Phillips, D. (1995) Evaluating Time-Lapse Video Evaluation Museum Management and Curatorship, 9: 1929. 
Reeves, M. (2002) Measuring the economic and social impact of the arts: a review, Arts Council of England, London.

Resource (2004) Guide to the Use of CCTV in Museums, Archives and Libraries, London http://www.resource.gov.uk

Rounds, J. (2001) Is there a Core Literature in Museology? Curator 44(2): 194-206.

Schensul, S.L., J.J. Schensul and M.D. LeCompte (1999) Essential Ethnographic Methods: Observations, Interviews and Questionnaires. Walnut Creek CA: AltiMira Press.

Schubert, K. (2000) The Curator's Egg-The Evolution of the Museum Concept from the French Revolution to the Present Day. New York: One-Off Press.

Serrell, B. (1998) Paying Attention: Visitors and Museum Exhibitions. Washington: AAM.

Shettel, H. (1968) Strategies for determining exhibit effectiveness (AIR E95-4-68-FR) Pittsburgh, PA: American Institute for Research.

Smith, J. K. and L. Wolf (1996) Museum visitor preferences and intentions in constructing aesthetic experience. Poetics 24: 219-238

Stidworthy, I (2004) Artist's Talk, ICA London, April.

Taylor, N. (2002) State Surveillance and the Right to Privacy Surveillance and Society 1(1): 66-85. http://www.surveillance-and-society.org/articles1/statesurv.pdf

Touliatos, J., B.F. Perlmutter and M. Straus (1990) Handbook of Family Measurement Techniques. London: Sage.

Ueki, K. (1998) Shaping the Experience of Art: Art Museums and Curatorial Intentions. Unpublished MPhil Thesis, University of Manchester.

Vom Lehn, D., C. Heath and J. Hindmarsh (2002) Video-based Field studies in Museums and Galleries Visitor Studies Today Fall.

Vom Lehn., D., C. Heath and H. Knoblauch (2001) Configuring Exhibits: The Interactional Production of Experience in Museums and Galleries. In H. Knoblauch and H. Kotthoff (eds.) (2001) Verbal Art Across Cultures: Aesthetics and Proto-Aesthetics of Communication Tubingen: Gunter, Narr Verlag, pp. 281-297. 